\title{
A design of wideband high-power 3-dB quadrature coupler using defected ground structure for status data transmitting system
}

\author{
The Anh Nguyen Dinh ${ }^{1}$, Long Hoang Duc ${ }^{2}$, Duong Bach Gia ${ }^{3}$, Dragos Dancila ${ }^{4}$ \\ ${ }^{1}$ Vietnam National Space Center, Vietnam Academy of Science and Technology \\ ${ }^{2,4}$ Department of Engineering Sciences, Solid State Electronics, Uppsala University, Sweden \\ ${ }^{3}$ VNU University of Engineering and Technology, Hanoi, Vietnam
}

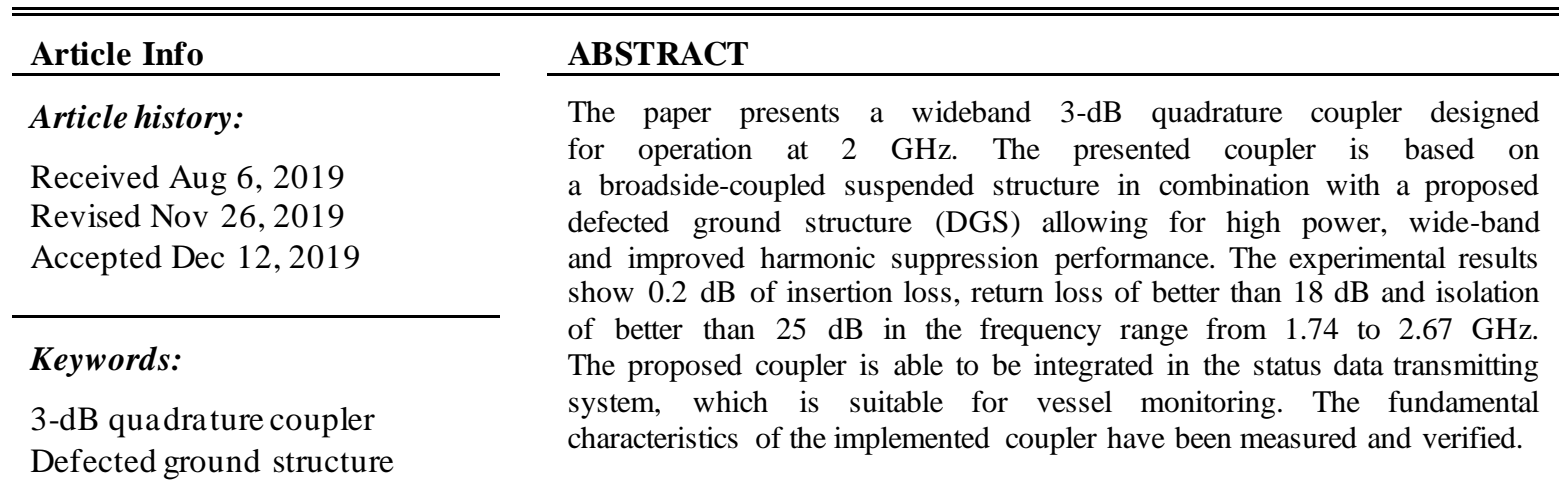

Divider

RF combiner

Status data transmitting system

Vessel monitoring system

This is an open access article under the CC BY-SA license.

\section{Corresponding Author:}

The Anh Nguyen Dinh,

Vietnam National Space Center,

VNSC Building (A6), No. 18-Hoang Quoc Viet Street-Hanoi-Vietnam.

Email: ndtanh@vnsc.org.vn

\section{INTRODUCTION}

High power, wide bandwidth, low-loss combiners or dividers with an average power handling capability of hundreds of Watts are used generally for combining high power amplifiers. The functionality of the coupler is to combine two input signals which have equivalent power levels and with a 90 degree relative phase difference. It can also separate an incoming signal into two output signals with similar amplitudes and a phase difference of 90 degrees.

Various methods are proposed to improve the performance of couplers [1-9]. Most of them are applied to low power systems. Typically, a 3-dB quadrature coupler which is suitable for printed circuit board implementation presented in [1]. It shows that the coupler can reduce the drawbacks of conventional thin-film microstrip line Lange coupler with the advantages of coplanar waveguide coupled line structures. Another 3-dB quadrature coupler using broadside-coupled coplanar waveguides [2] illustrates that the coupler with a broadside-coupled structure can easily be designed on a single-layer substrate printed circuit board, without using multi-layer substrates. However, such low-power couplers cannot be used directly for high power applications, because of the field breakdown effect [10] and thermals issues with the coupler.

Defected Ground Structures (DGS) have been proposed for microwave applications such as filters [11-15], amplifiers [16], antennas [17-18], and wireless power transfers [19]. In this paper, we propose a new coupler design for high power applications, adopting a broadside-coupled suspended 
structure (BSS) and a defected ground structure (DGS) to improve bandwidth, reduce insertion loss and offer a truly high power solution. The proposed coupler is able to be integrated in the status data transmitting system, which is suitable for vessel monitoring [20-21]. The paper is organized as follow. Section 2 introduces the design considerations of the proposed coupler. The experimental results are provided in section 3 and discussed in the last section.

\section{THEORY AND DESIGN}

The presented power combiner is based on a broadside-coupled air suspended strip-line (BSS), realizing a tightly coupled structure. A 3-D drawing of the combiner is shown in Figure 1. The BSS structure is characterized by two transmission lines in which $Z_{0, e}$ and $Z_{0,0}$ are respectively the even and odd characteristic impedances. Expressions for the mode characteristic impedances, coupling ratio (C) and characteristic impedance $\left(\mathrm{Z}_{0}\right)$ are given as following [22-23]:

$$
\begin{aligned}
& Z_{0, e}=Z_{0} \sqrt{\frac{1+C}{1-C}} \\
& Z_{0, o}=Z_{0} \sqrt{\frac{1-C}{1+C}} \\
& Z_{0}=\sqrt{Z_{0, e} \times Z_{0, o}}
\end{aligned}
$$

The dimensions of the structure are determined for a given dielectric substrate and substra te thickness following $[22,24]$ :

$$
\begin{aligned}
& \frac{W}{b}=\frac{1}{\pi}\left[\ln \frac{1+M}{1-M}-\frac{S}{b} \ln \frac{1+\frac{M}{k}}{1-\frac{M}{k}}\right] \\
& \frac{S}{b}=0.0017 Z_{o} \sqrt{\epsilon_{r}}\left(\frac{1-C}{1+C}\right)^{1 / 2} \ln \frac{1+k}{1-k}
\end{aligned}
$$

Where,

$$
\begin{aligned}
& M=\left[\left(k \frac{b}{S}-1\right) /\left(\frac{1}{k} \frac{b}{S}-1\right)\right]^{1 / 2} \\
& N=\frac{60 \pi}{z_{0} \sqrt{\epsilon_{r}}}\left(\frac{1-C}{1+C}\right)^{1 / 2}
\end{aligned}
$$

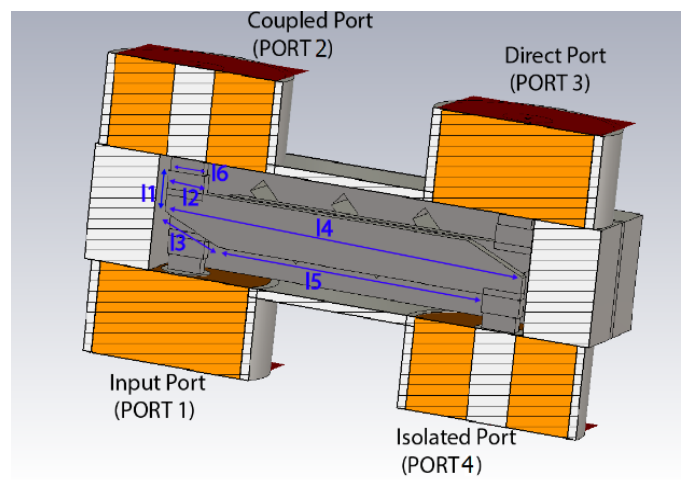

(a)

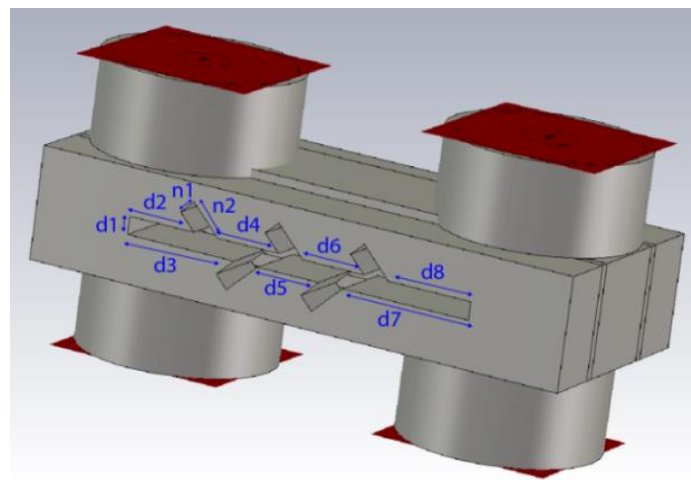

(b)

Figure 1.(a) The 3D drawing of the presented quadrature couplerat $2 \mathrm{GHz}$, (b) The proposed DGS structure introduces the tree-shaped ground slot patterning in the $3 \mathrm{D}$ model 
for $N \leq 1$

$$
k=\left[1-\left(\frac{0.5 \exp (\pi N)-1}{0.5 \exp (\pi N)+1}\right)^{4}\right]^{1 / 2}
$$

for $N \geq 1$

$$
k=\left(\frac{0.5 \exp (\pi N)-1}{0.5 \exp (\pi N)+1}\right)^{2}
$$

For a given coupling ratio with air as dielectric substrate $\left(\epsilon_{r}=1\right)$, the ratios $S / b$ and $W / b$ can be computed following the formulas (4) and (5) in which S, b, and $\mathrm{W}$ are def ined in Figure 2. For the 3-dB coupler design, the initial dimensions are obtained as follows: $\mathrm{W}=6.9 \mathrm{~mm}, \mathrm{~b}=6.35 \mathrm{~mm}, \mathrm{~S}=1.4 \mathrm{~mm}, \mathrm{t}=0 \mathrm{~mm}$. Due to Ohmic loss characteristics at a high-power level, the thickness of strip conductors is increased to $1.5 \mathrm{~mm}$, thus allowing an improved average power handling capability. Though, the high thickness of the strip conductors takes adverse effect on the accuracy of the formulas (4) and (5). The thickness correction is numerically calculated by using the computer-aided design software CST. The numerical results of the structural dimensions of the coupler are given as follows: $W=5.4 \mathrm{~mm}, b=10.8 \mathrm{~mm}, \mathrm{~S}=0.8 \mathrm{~mm}$ forthe $1.5 \mathrm{~mm}$ of strip conductor thickness. The proposed tree-shaped defected ground structure (DGS) in association with a bevel at the corner edge of each strip conductors allows improving the bandwidth as well as the harmonic rejection as shown in Figure 1(a) and Figure 1(b). A trade-off between bandwidth and average power handling capability must be taken into consideration using beveling techniques. This reduces the high strength of the electric field at the beveled edges as shown in Figure 3 . The tree-shaped structure is symmetrically placed at the top and bottom of the ground plane as shown in Figure 1(b).

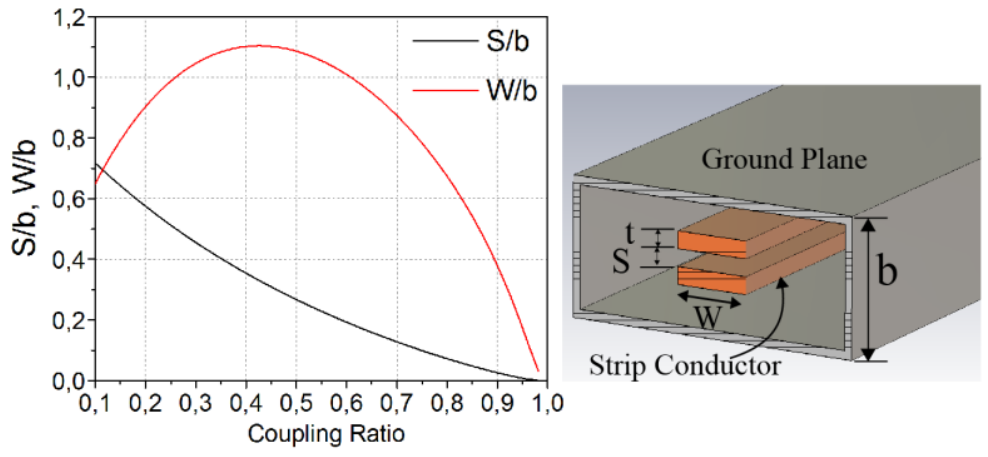

Figure 2. Variations of $\mathrm{S} / \mathrm{b}$ and $\mathrm{W} / \mathrm{b}$ as a function of coupling ratio with air substrate (left).

Geometry of broadside-coupled suspended strip-line (right) in which $\mathrm{S}$ is the space between strip conductors, $t$ is the thickness of conductors, $\mathrm{W}$ is the width of strip conductors, and $b$ is the ground spacing

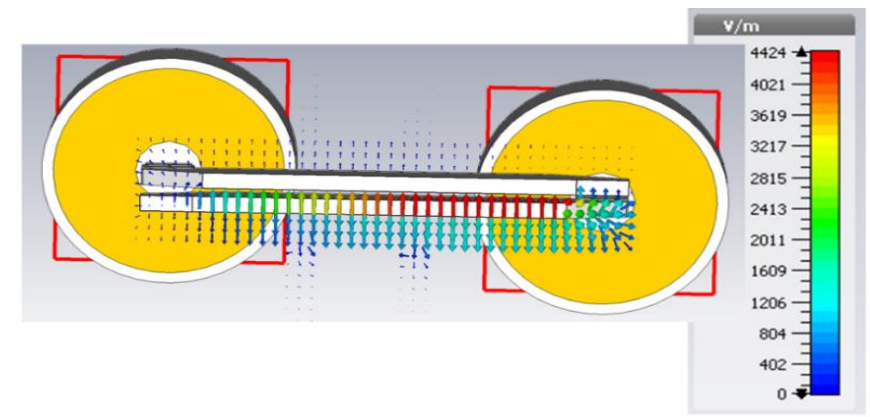

Figure 3. The electric field lines pattern (cross-view). The simulation is performed using a signal of $1 \mathrm{~W}$ fed into the output 
The design of a conventional hybrid coupler based on the calculated dimensions is adapted considering the bevel technique, as to extend the bandwidth, which is normally from $400 \mathrm{MHz}$ to $600 \mathrm{MHz}$ for other combiners. We propose further optimization of the design using the new DGS structure, without any changes in the coupling structure realized previously.

Table1. Typical defected ground structures

\begin{tabular}{|c|c|c|c|c|c|}
\hline Case & DGS structure & $\begin{array}{c}\text { Bandwidth } \\
(\mathrm{MHz})\end{array}$ & Case & DGS structure & $\begin{array}{c}\text { Bandwidth } \\
(\mathrm{MHz})\end{array}$ \\
\hline 1 & & 715 & 5 & & 875 \\
\hline 2 & & 867 & 6 & & 720 \\
\hline 3 & & 890 & 7 & & 843 \\
\hline 4 & & 834 & 8 & & 930 \\
\hline
\end{tabular}

The optimization of the DGS structure is implemented following a set of requirements, i.e. bandwidth, S parameters, power handling capability (RF breakdown), etc. Table 1 illustrates some typical Defected Ground Structures with corresponding simulated bandwidths. In our design, the tree-shaped structure is optimally designed with 5 branches using the CST simulation software. For the presented coupler design, the final simulation parameters are: $11=4.35 \mathrm{~mm} ; 12=4.5 \mathrm{~mm}$; the bevel length $13=7.39 \mathrm{~mm}$, for the initial design the bevel length is $0 \mathrm{~mm}$; the length of the strip conductor is a quarter-wavelength at $2 \mathrm{GHz} ; 14=42 \mathrm{~mm} ; 15=30.5 \mathrm{~mm} ; 16=4 \mathrm{~mm}$, in which 12 and 16 are step matching sections at ports; the spacing grounds $b=10.8 \mathrm{~mm}$; the spacing between strip-lines $\mathrm{S}=0.8 \mathrm{~mm} ; \mathrm{d} 1=2 \mathrm{~mm} ; \mathrm{d} 2=7.5 \mathrm{~mm}$; $\mathrm{d} 3=12.5 \mathrm{~mm} ; \mathrm{d} 4=7.17 \mathrm{~mm} ; \mathrm{d} 5=7.17 \mathrm{~mm} ; \mathrm{d} 6=7.17 \mathrm{~mm} ; \mathrm{d} 7=14.5 \mathrm{~mm} ; \mathrm{d} 8=9.5 \mathrm{~mm} ; \mathrm{n} 1=2 \mathrm{~mm} ; \mathrm{n} 2=4.5 \mathrm{~mm}$. The strip-line and the housing are made of copper. The overall dimension of the coupler is $30 \mathrm{~mm} \times 65 \mathrm{~mm} \times 38 \mathrm{~mm}$ (WxLxh). The electric field pattern of the combiner is described in Figure 3 for $1 \mathrm{~W}$ output power. For $1 \mathrm{~kW}$ signal, this translates into $\mathbf{0 . 1 2 6} \mathbf{~ M V} / \mathrm{m}$ of the maximum E-field, which is lower than the threshold breakdown electric field of the dry air [10]. The simulated results are demonstrated in Figure 4 for both cases with and without the DGS structure. It is clear that using DGS in the coupler design has remarkable advantages in term of bandwidth and return loss improvement.

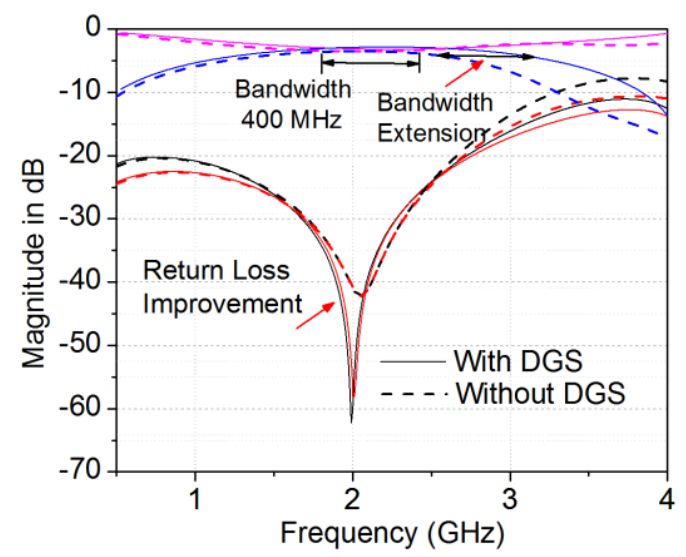

Figure 4. The simulated results of the coupler as function of frequency with and without DGS

\section{RESULTS AND DISCUSSION}

The fabricated coupler is designed at the center operating frequency of $2 \mathrm{GHz}$ as shown in Figure 5 . We use the PNA-N5221A vector network analyzer (VNA) to measure the S-parameters of the combiner. The simulated and measured results are in good agreement a s shown in Figure 6. The bandwidth is mea sured up to $930 \mathrm{MHz}$. The insertion loss is measured on the order of $-3.02 \pm 0.2 \mathrm{~dB}$. The maximum return loss 
at port 1 and 3 are measured approximately $40 \mathrm{~dB}$, while on the order of $30 \mathrm{~dB}$ at port 2 and 4 due to a sligh $t$ mismatch between the conductor of the coaxial connector and the transmission lines. It results from the manualassembly.

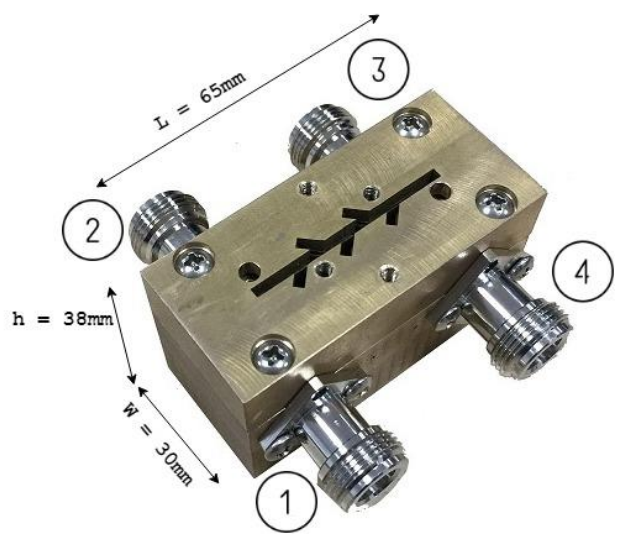

Figure 5. The proposed DGS-coupler is shown

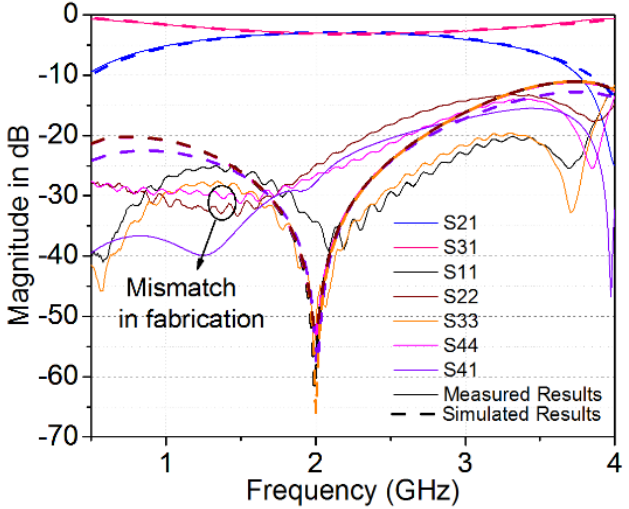

Figure 6. A comparison of the simulated and measured results of the coupler is shown

The phase shift between ports is illustrated in Figure 7. The phase shift between two Output ports of coupler is $90 \pm 1$ degree. There is a high agreement between the simulation result and the measurement result. Our results are compared with the recent published work in Table 2. It can be seen that the power handling capacibility can reach to $1 \mathrm{~kW}$ by using copper busbar for transmission line. The bandwidth and return loss can be improved by using DGS. Thus, our coupler can be used in the status data transmitting system as presented in [20-21].

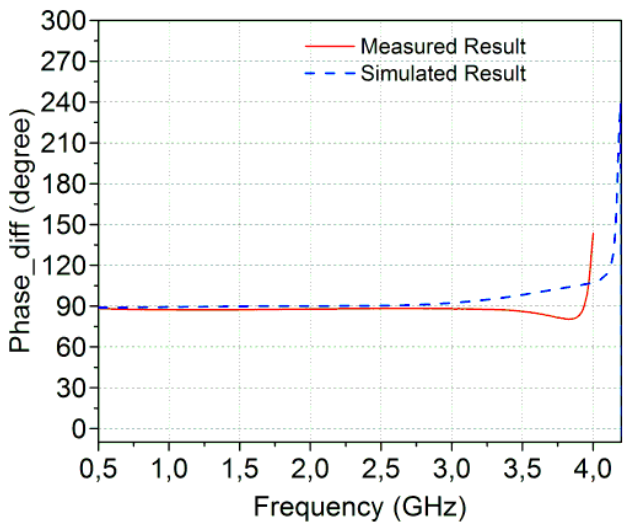

Figure 7. Phase shift among ports

Table 2. The comparison between our research and previous published researchs

\begin{tabular}{cccccccc}
\hline References & $\begin{array}{c}\text { Frequency } \\
(\mathrm{MHz})\end{array}$ & $\begin{array}{c}\text { Bandwidth } \\
(\mathrm{MHz})\end{array}$ & $\begin{array}{c}\text { Power Handling } \\
\text { Capability }(\mathrm{W})\end{array}$ & $\begin{array}{c}\text { Insertion } \\
\text { Loss }(\mathrm{dB})\end{array}$ & $\begin{array}{c}\text { Isolation Loss } \\
(\mathrm{dB})\end{array}$ & $\begin{array}{c}\text { Return Loss } \\
(\mathrm{dB})\end{array}$ & $\begin{array}{c}\text { Manufacture } \\
\text { Material }\end{array}$ \\
\hline$[1]$ & $1800 \div 2800$ & 1000 & - & $3 \div 0.1$ & Better than 20 & $\begin{array}{c}\text { Better than } \\
20\end{array}$ & $\begin{array}{c}\text { Printed Circuit } \\
\text { Board (PCB) }\end{array}$ \\
{$[2]$} & $2100 \div 2700$ & 600 & - & $3.2 \div 0.1$ & Better than 19 & $\begin{array}{c}\text { Better than } \\
19\end{array}$ & PCB \\
{$[25]$} & $1770 \div 2200$ & 570 & - & $3 \div 0.5$ & Better than 20 & $\begin{array}{c}\text { Better than } \\
20\end{array}$ & PCB \\
{$[26]$} & $2000 \div 2800$ & 800 & - & $3 \div 1$ & Betterthan 14 & $\begin{array}{c}\text { Better than } \\
15\end{array}$ & PCB \\
{$[$ This work $]$} & $1740 \div 2670$ & 930 & Up to 1 kW & $3.02 \div 0.2$ & Better than 25 & $\begin{array}{c}\text { Better than } \\
18\end{array}$ & Copper BusBar \\
\hline
\end{tabular}




\section{CONCLUSION}

We analyzed and successfully designed a 3-dB coupler using a newly proposed DGS structure. Our coupler has a bandwidth of $930 \mathrm{MHz}$. The insertion loss, return loss, a nd isolation loss of this coupler are $3.02 \div 0.2,18 \mathrm{~dB}$ and $25 \mathrm{~dB}$ respectively. The power handling capability of the design can further be improved by choosing the higher thickness of the strip-conductors and the proper connectors, i.e. 7/16 type. The design methodology can be applied to any frequency range of interest up to $3 \mathrm{GHz}$, and it could be adapted for other combining structures such as e.g. the Wilkinson and Gysel types, as to expand their nominal bandwidths. The results prove that our coupler can be used in the status data transmitting system.

\section{ACKNOWLEDGEMENTS}

This research is granted by Vietnam Space Science and Technology Program through the national projects titled "Research, Design, Integrate, Launch and Operate a Nano Satellite-VT-CN.02/17-20".

\section{REFERENCES}

[1] J. Chiu, C. Lin and Y. Wang, "A 3-dB quadrature coupler suitable for PCB circuit design," in IEEE Transactions on Microwave Theory and Techniques, vol. 54, no. 9, pp. 3521-3525, Sept. 2006.

[2] C. Chang, J. Chiu, H. Chiu and Y. Wang, "A 3-dB quadrature coupler using broadside-coupled coplanar waveguides," inIEEE Microwave and Wireless Components Letters, vol. 18, no. 3, pp. 191-193, March 2008.

[3] Jikwon Kim, and Jong-GwanYook, "A miniaturized 3 dB 90degree hybrid coupler using coupled-line section with spurious rejection," in IEEE Microwave and Wireless Components Letters, vol.24, no.11, pp. 766-768, November 2014

[4] S. Jung, R. Negra and F. M. Ghannouchi, "A design methodology for miniaturized 3-dB branch-line hybrid couplers using distributed capacitors printed in the inner area," in IEEE Transactions on Microwave Theory and Techniques, vol. 56, no. 12, pp. 2950-2953, Dec. 2008

[5] K. M. Cheng and S. Yeung, "A novel rat-race coupler with tunable power dividing ratio, ideal port isolation, and return loss performance," inIEEE Transactions on Microwave Theory and Techniques, vol. 61, no. 1, pp. 55-60, Jan. 2013.

[6] S. I. Shams and A. A. Kishk, "Design of 3-dB hybrid coupler based on RGW technology," inIEEE Transactions on Microwave Theory and Techniques, vol. 65, no. 10, pp. 3849-3855, Oct. 2017.

[7] S. Liao and J. Peng, "Compact planar microstrip branch-line couplers using the quasi-lumped elements approach with nonsymmetrical and symmetrical T-shaped structure," inIEEE Transactions on Microwave Theory and Techniques, vol. 54, no. 9, pp. 3508-3514, Sept. 2006.

[8] Kai-Yu Tsai, Hao-Shun Yang, Jau-Horng Chen, and Yi-Jan Emery Chen, "A miniaturized 3 dB brand-line hybrid coupled with harmonics suppression," in IEEE Microwave and Wireless Components Letters, vol. 21, no. 10, pp. 537-539, October 2011.

[9] H. Yoon and B. Min, "Two section wideband $90^{\circ}$ hybrid coupler using parallel-coupled three-line," in IEEE Microwave and Wireless Components Letters, vol. 27, no. 6, pp. 548-550, June 2017.

[10] L. Gould and L. W. Roberts et al., "Breakdown of air at microwave frequencies,"J. Appl. Phys., vol. 27, no. 10, pp. 1162-1170, 1956.

[11] A. Abdel-Rahman, A. K. Verma, A. Boutejdar and A. S. Omar, "Compact stub type microstrip bandpass filter using defected ground plane," inIEEE Microwave and Wireless Components Letters, vol. 14, no. 4, pp. 136-138, April 2004

[12] D. Ahn, J. Park, C. Kim, J. Kim, Y. Qian and T. Itoh, "A design of the low-pass filter using the novel microstrip defected ground structure," inIEEE Transactions on Microwave Theory and Techniques, vol. 49, no. 1, pp. 86-93, Jan. 2001.

[13] M. K. Mandal and S. Sanyal, "A novel defected ground structure for planar circuits," in IEEE Microwave and Wireless Components Letters, vol. 16, no. 2, pp. 93-95, Feb. 2006.

[14] S. U. Redman, A. F. Sheta, and M. Alkanhal, "Compact bandstop filter using defected ground structure,"in Proc. Saudi Int. Electron. Commun. Photon. Conf. (SIECPC), pp. 1-4, Apr, 2011.

[15] Jiayuan $\mathrm{Lu}$, Jianpeng Wang and Hui Gu, "Design of compact balanced ultra-wideband bandpass filter with half mode dumbbell DGS,"Electronics Letters 28 $8^{\text {th }}$, Vol. 52, No. 9, pp. 731-732, April 2016.

[16] Jong-Sik Lim, Ho-Sup Kim, Jun-Seek Park, Dal Ahn and Sangwook Nam, "A power amplifier with efficiency improved using defected ground structure," inIEEE Microwave and Wireless Components Letters, vol. 11, no. 4, pp. 170-172, April 2001.

[17] Y. J. Sung, M.Kim, and Y.S.Kim, "Harmonics reduction with defected ground structure for a microstrip patch antenna," inIEEE Antennas and Wireless Propagation Letters, vol. 2, pp. 111-113, 2003.

[18] Debatosh Guha, Chandrakanta Kumar, and Surendra Pal, "Improved cross-polarization characteristics of circular microstrip antenna employing arc-shaped Defected Ground Structure (DGS)," inIEEE Antennas and Wireless Propagation Letters, vol. 8, pp. 1367-1369, 2009.

[19] S. Hekal, A. B. Abdel-Rahman, H. Jia, A. Allam, A. Barakat and R. K. Pokharel, "A novel technique for compact size wireless power transfer applications using defected ground structures," in IEEE Transactions on Microwave Theory and Techniques, vol. 65, no. 2, pp. 591-599, Feb. 2017. 
[20] The Anh Nguyen Dinh, Le Xuan Huy, Tuan Anh Vu, and Duong Bach Gia, "A status data transmitting system for vessel monitoring,"International Journal of Electronic and Computer Engineering (IJECE), vol. 8, no. 2, pp. 917-925, April 2018.

[21] The Anh Nguyen Dinh, Minh Ngo Duc, Duong Bach Gia, "Design of an S-band vessel monitoring system using satellites,"International Journal of Applied Engineering Research, Vol. 13, No. 8, 2018, pp. 6063-6068.

[22] I. J. Bahl and P. Bhartia, "The design of broadside-coupled stripline circuits," inIEEE Transactions on Microwave Theory and Techniques, vol. 29, no. 2, pp. 165-168, Feb. 1981.

[23] David M. Pozar, "Microwave Engineering $4^{\text {th }}$ ed," John Wiley \& Sons, Inc., 2012.

[24] S. B. Cohn, "Thickness corrections for capacitive obstacles and strip conductors," inIRE Transactions on Microwave Theory and Techniques, vol. 8, no. 6, pp. 638-644, November 1960.

[25] L. Wang, G. Wang and J. Sidén, "High-performance tight coupling microstrip directional coupler with fragmenttype compensated structure," in IET Microwaves, Antennas \& Propagation, vol. 11, no. 7, pp. 1057-1063, 2017.

[26] K. Ding and A. Kishk, "Wideband hybrid coupler with electrically switchable phase-difference performance," in IEEE Microwave and Wireless Components Letters, vol. 27, no. 11, pp. 992-994, Nov. 2017.

\section{BIOGRAPHIES OF AUTHORS}

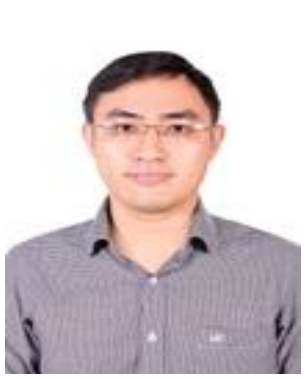

The Anh Nguyen Dinh received the B.S Degree and M.Sc Degree in Electronics and Telecommunications Technology from University of Engineering and Technology, Vietnam National University in 2009 and 2011, respectively. From 2012 to 2015, he was a researcher in Communications and Television Develoment., JSC. Since 2016, he has been a researcher in Vietnam Space Center, Vietnam Academy of Science and Technology. Now, he is a Ph.D student in Vietnam National University. His researches are in fields of microwave engineering, communications in satellites, ground station and radio systems.

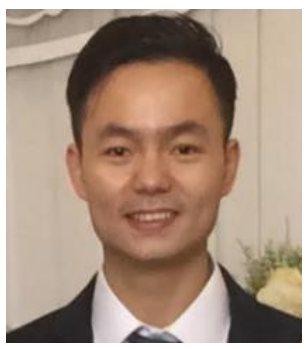

Long Hoang Duc was born in Hanoi, Vietnam, in 1987. He received the bachelor's degree (Hons.) in electronics and telecommunications from the University of Engineering and Technology (UET), VNU, in 2009, and the M.Sc. degree from Poles UniversitairesFrancais Hanoi in 2012. He is currently pursuing the Ph.D. degree at FREIA laboratory, Uppsala University Sweden. His current research interests include the area of RF PA design.

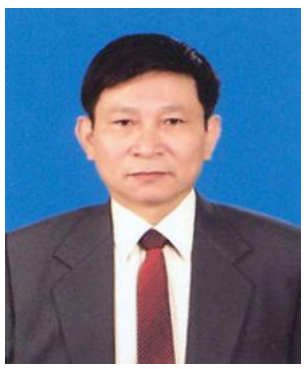

Duong Bach Gia Ph.D degree in wireless physics from University of HaNoi in 1988. From 1988 to 1990 , he was a researcher assisstant in Leningrad University, Russia. From 1991 to 2005, he was a researcher in academy of air force. He has been a lecturer and head of electronics and telecommunications center, University of Engineering and Technology, Vietnam National University since 2006. He was promoted to Associate Professor in 2009 and to Professor in 2016. His research forcuses on RF analog singal processing, RF chip design, radar engineering and technology, automatic control. Email: duongbg@vnu.edu.vn.

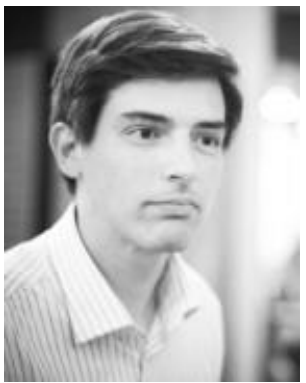

Dragos Dancila received the electrical engineering degree from the Universitcatholique de Louvain (UCL), Louvain-la-Neuve, Belgium, in 2006, and the Ph,D. degree in applied sciences from UCL in collaboration with IMEC, Leuven, Belgium, in 2011. Currently, he is an Associate Lecturer with the Microwave Group at the Department of Engineering Sciences, Solid State Electronics, Uppsala University, Uppsala, Sweden, where he is also a Researcher with the FREIA Laboratory, and is involved in solid-state RF power amplifier development. His current research interests include adaptive and integrated antennas, RF-MEMS technology, and RF sensors for biomedical applications, such as skin cancer detection and glucose monitoring. 